This item was submitted to Loughborough's Research Repository by the author.

Items in Figshare are protected by copyright, with all rights reserved, unless otherwise indicated.

\title{
Elasto-multi-body dynamics of internal combustion engines with tribological conjunctions
}

PLEASE CITE THE PUBLISHED VERSION

http://dx.doi.org/10.1243/14644193JMBD242

PUBLISHER

Professional Engineering Publishing / @ IMECHE

VERSION

VoR (Version of Record)

LICENCE

CC BY-NC-ND 4.0

REPOSITORY RECORD

Perera, M.S. Malika, Stephanos Theodossiades, and Homer Rahnejat. 2019. "Elasto-multi-body Dynamics of Internal Combustion Engines with Tribological Conjunctions”. figshare. https://hdl.handle.net/2134/6648. 
This item was submitted to Loughborough's Institutional Repository (https://dspace.lboro.ac.uk/) by the author and is made available under the following Creative Commons Licence conditions.

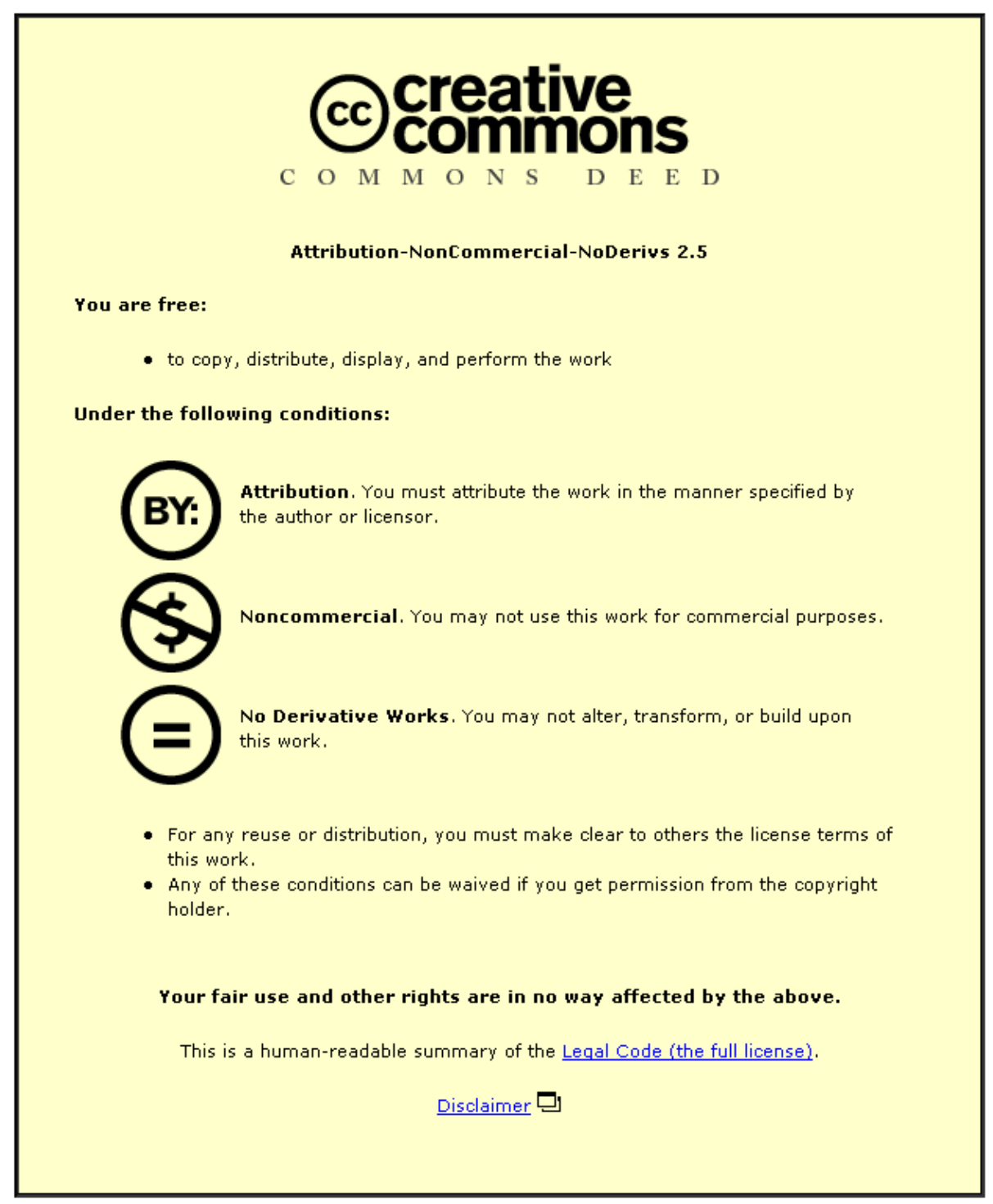

For the full text of this licence, please go to: http://creativecommons.org/licenses/by-nc-nd/2.5/ 


\title{
Elasto-multi-body dynamics of internal combustion engines with tribological conjunctions
}

M S M Perera, S Theodossiades, and H Rahnejat*

Wolfson School of Mechanical and Manufacturing Engineering, University of Loughborough, Loughborough, UK

The manuscript was received on 2 October 2009 and was accepted after revision for publication on 8 March 2010.

DOI: $10.1243 / 14644193 J M B D 242$

\begin{abstract}
Reduction of frictional losses and NVH (Noise, Vibration, and Harshness) refinement constitute the key customer-focussed aims in internal combustion engine development. Numerical predictive tools have progressively become an important part of achieving these aims. However, the interactions and sometimes the conflicting requirements of the aforementioned objectives call for the inclusion of many phenomena in realistic models of practical significance. These phenomena occur at varying physics of scale, from micro-scale tribological conjunctions to small scale vibrations and onto large scale inertial dynamics. At the same time, the inclusion of many disciplines for a cohesive analysis will be required, such as rigid body dynamics and elastodynamics, as well as tribology. While the inclusion of such a multi-disciplinary approach is deemed essential, the use of analytical rather than numerical models, as far as possible, would render realistic predictions within the usual tight industrial timescales. This article presents an experimentally validated model of the engine piston assembly, which is based on the multiphysics, multi-scale nature of the interacting components. Furthermore, it provides predictions of some current development trends in engines such as the high output power to weight ratio and offset crankshaft. The emphasis of this article is on the integration of the kinetic reactions arising from the tribological conjunction of the dynamics of engine subsystems, piston, and crankshaft.
\end{abstract}

Keywords: tribo-elasto-multi-body dynamics, internal combustion engines, engine NVH, offset crankshaft

\section{INTRODUCTION}

A growing competition pervades the automobile sector. In particular, the trend is to develop high output power-to-light weight compact engines in a short time from concept to production. These key requirements in a market with diminishing returns on investment mean that a greater emphasis is put on virtual prototyping simulations. At the same time, practical realities in a consumer-driven market mean that models should be able to address the key issues of concern, such as fuel efficiency and NVH refinement. With simulations of multi-body dynamics, opportunities to develop detailed models have arisen, particularly in the past decade. However, the initial models, mostly

\footnotetext{
*Corresponding author: Wolfson School of Mechanical and Manufacturing Engineering, University of Loughborough, Loughborough, Leicestershire LE11 3TU, UK.

email:h.rahnejat@lboro.ac.uk
}

employed in industry, lacked key features to address issues such as assessment of mechanical losses and NVH performance.

Combustion is the prominent noise source in an engine, while heat transfer and friction account for major engine inefficiencies. The maximum combustion pressure occurs in the power stroke, whereas its lowest value is observed in suction. Also, flame propagation through the cylinder is not spontaneous as it is intended, thus creating pressure fluctuations. These cyclic variations create excitations with varying amplitudes and spectral composition. During power generation it is necessary to induce a rotary motion from the work done by the piston. A piston-connecting rodcrankshaft system converts this translational motion into a rotational action. This transformation produces harmonic responses as multiples of crankshaft rotational frequency, referred to as engine orders [1]. The fluctuations in power torque output often lead to $\mathrm{NVH}$ concerns, particularly with high torque diesel engines, another important trend in engine development. 
These concerns include transmission rattle [2], clutch in-cycle vibration [3], and cabin boom [4]. These are direct consequences of progressive use of lighter materials of low structural damping in engines and drive trains [1]. Elastodynamic behaviour of materials of low elastic modulus results in a broad spectrum of vibration at multiples of engine order, even though the overall magnitude of vibration is reduced due to the decreased inertia [5]. Half engine order harmonics, referred to as engine roughness (multiples of combustion fundamental) creep into the spectrum of vibration $[\mathbf{1}, \mathbf{5}]$.

The other sources of engine inefficiency - parasitic frictional losses - account for 25 per cent of all the losses, and some of the tribological shortcomings within the engine contribute to or are also responsible for significant NVH concerns [6]. These include the age old problems of engine bearing whirl instability $[\mathbf{7}, 8]$ and piston slapping action $[\mathbf{1}, 4]$. In order to reduce the effect of piston slap, traditionally the centre of the gudgeon pin is offset by a small amount from the centre-line of the piston in an attempt to adhere the piston to the thrust side. However, this can also increase friction by reducing the film thickness between the ring-pack and cylinder liner. Similarly, to reduce whirl, the main crankshaft bearings are designed with tight clearances to run at high eccentricity ratios. The drawback is often increased friction due to high generated temperatures. Therefore, the interactive nature of a host of phenomena is apparent, requiring a multi-scale multi-physics analysis. Such an analysis within a multi-body dynamics environment was initiated by Zeischka et al. [9] and Boysal and Rahnejat [10] and is extended here, in all cases for the piston-connecting rod-crank subsystem. Here, however, modal elastic behaviours of components are taken into account, as well as thermal effects influencing the behaviour of piston-liner, and engine bearing conjunctions. In addition, in recent years, crankshaft offset is considered as a palliation against secondary motions of the piston, while reducing the effect of friction in a piston-liner conjunction [11], for which a dearth of analysis still exists. This article addresses this issue as well.

\section{MULTI-SCALE MULTI-PHYSICS ENGINE MODEL}

The overall engine model comprises features to capture certain interactive phenomena. These include large displacement rigid body dynamics of the pistonconnecting rod-crank subsystem. These are represented by the primary and secondary motions of the piston relative to the cylinder bore, the oscillatory motion of the connecting rod, and the rotation of the crankshaft (see Fig. 1). To couple these degrees of

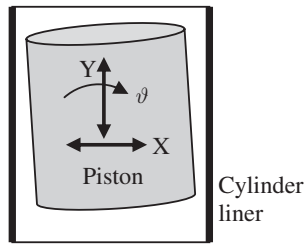

Piston

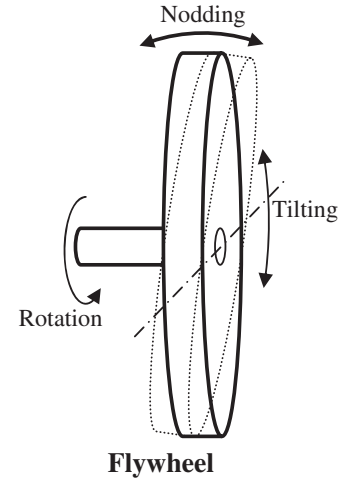

Fig. 1 Defined inertial motions of piston and crankshaft

freedom, the subsystem is modelled as a multi-body system, based on constrained Lagrangian dynamics. The translational motion of the piston is governed by the combustion gas force and the induced inertial forces of piston and the gudgeon pin, which are converted by the connecting rod to the rotation of the crank. The secondary motions of the piston within the confines of its clearance space in the cylinder are resisted by the conjunctional forces in the piston-bore contacts on the thrust and anti-thrust sides. These lateral and tilting motions are small amplitude oscillations. Transverse and torsional oscillations of the crankshaft also occur as the result of motions of its support journal-bearing centres relative to their bushings, fitted to the engine block, which is assumed to be rigid. No translational motion (axial float) of the crank-flywheel assembly is allowed in the model. The combined lateral and torsional motion of the crank-flywheel assembly results in the conical whirl motion which is responsible for many of the impact induced $\mathrm{NVH}$ phenomena down line of the engine in the drive train system, such as the in-cycle clutch vibration reported by Kushwaha et al. [3]. Therefore, the inertial dynamics of engine subsystems are due to gas pressure loading, inertial imbalance, and reactions from lubricated load-bearing conjunctions. Hence, the inclusion of representative tribological conditions within an engine model is crucial for a realistic predictive tool.

Another important feature is component flexibility, which induces structural response of flexible bodies within a multi-body system. A realistic model would have to include modal behaviour of the engine components of lighter construction, which are the connecting rod and crankshaft, particularly with modern engines. Therefore, the overall model comprises the physics of motion across a broad scale from large rigid body dynamics of piston primary motion and crankshaft angular rotation to small amplitude secondary motions, infinitesimal structural vibrations, and micro-scale localized contact deformations and/or lubricant film formation. This is the reason for multi-scale multi-physics analysis. 


\subsection{Inertial and structural dynamics}

It is clear that an interactive method is required to deal with the phenomena involved. Constrained Lagrangian dynamics deals with multi-body dynamics of an assembly of parts, which are constrained to ensure the functional behaviour of the subsystem considered. Inclusion of the elastic behaviour of certain system components can be achieved in a number of ways, the simplest form being the use of Eulerian beams [1]. Another approach will be the determination of flexibility by considering various modal behaviours. This approach has been highlighted by Okamura et al. [12] as dynamic stiffness matrix method (DSMM) and successfully applied in engine modelling [13]. Whatever be the method, elemental discretization is very important in order to capture the modal characteristics. This is particularly important with the growing trend in the use of engines of lighter constructions. A large number of elements would normally be required in order to capture the high-frequency structural modal responses of the system components, which increase the size of stiffness and mass matrices. Thus, the suitable approach is to undertake finite element modal analysis by the inclusion of sufficient number of elements of suitable type and select the modal responses at frequencies of interest to include in the multi-body analysis. The modal reduction and selection technique used here is the Craig-Brampton component mode synthesis (CMS) [14]. In this method, a component is divided into a set of interior normal and interior constrained modes. The interior modes are selected, based on the frequency range of interest in the analysis. Then, the two types of modes are combined by superposition, such that the overall displacement at each node can be obtained. This is called the modal neutral file (MNF) in the ADAMS terminology. The procedure used for the inclusion of structural modes into multi-body analysis is detailed in reference [15]. The engine model is developed in ADAMS, where each part is represented by a marker located at the centre of gravity of the part with relevant inertial properties and orientation. These parts are connected to each other by holonomic or non-holonomic constraints. Figure 2 shows an overview of the single-cylinder engine model. The model consists of the piston, connecting rod, crankshaft, and the flywheel. The crankshaft is supported by three main crankshaft support bearings with two at the flywheel end and one at the other end of the crankshaft. The crankshaft is rigidly connected to the flywheel. The main bearing reaction forces are included in the model, using short bearing approximation with half-Sommerfeld boundary conditions (see section 2.2.1). Crankshaft and the connecting rod are assembled through a cylindrical joint, allowing free rotation around the crankpin. The piston and connecting rod are connected through a revolute joint, while the piston is connected to the ground through a planar joint, allowing it to move freely in the lateral direction within the confine of cylinder bore. Detailed development procedure for the above mentioned contact conjunctions are presented by Perera et al. [15]. The piston lateral movements are resisted by the lubricant reaction forces from the piston-liner interactions at the thrust and anti-thrust sides (see section 2.2.1). The model comprises 136 degrees of freedom, including 90 rigid

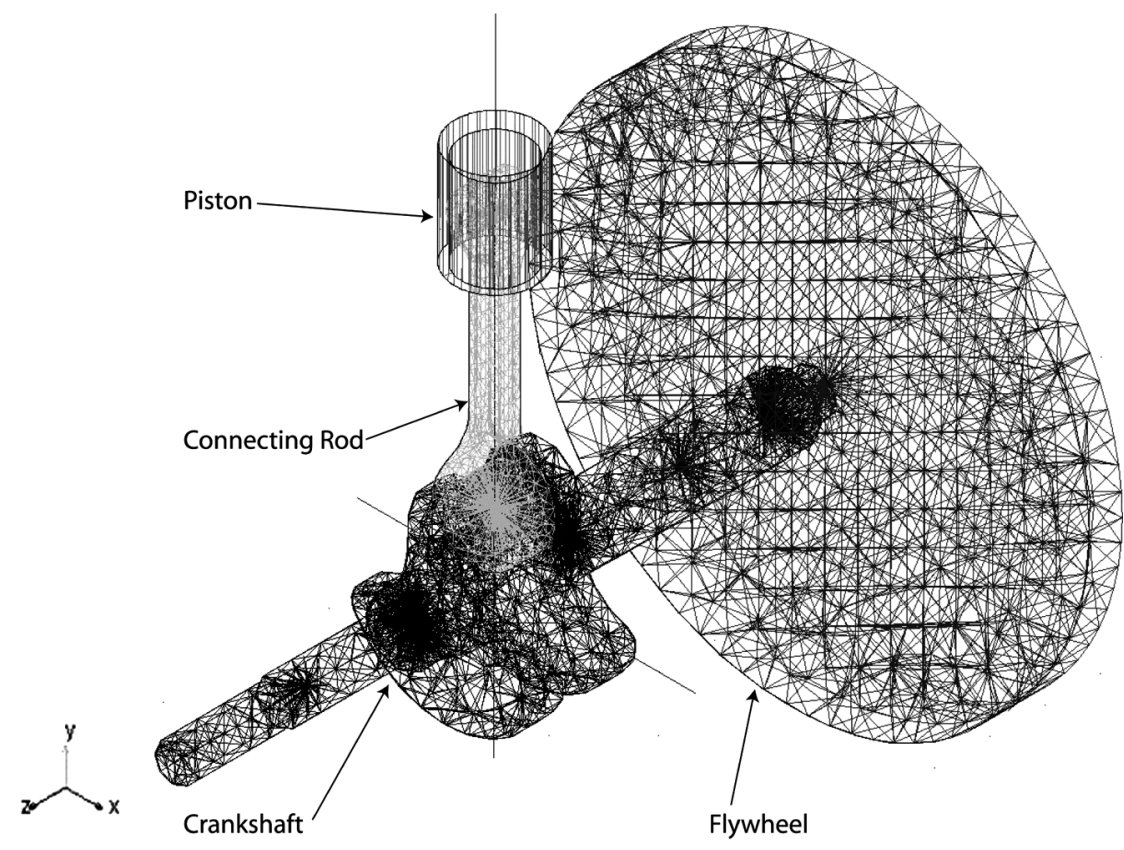

Fig. 2 The elastic multi-body model 
body motions and 154 structural modal behaviours [15]. These are represented by a differential-algebraic set of equations [1]

$$
\left\{\begin{array}{l}
\frac{\mathrm{d}}{\mathrm{d} t}\left(\frac{\partial T}{\partial \dot{q}}\right)-\frac{\partial T}{\partial q}+\frac{\partial V}{\partial q}+\sum_{n=1}^{m} \lambda_{n} \frac{\partial C_{n}}{\partial q}=F_{n \mathrm{c}} \\
C_{n}=0
\end{array}\right.
$$

where the generalized co-ordinates in the Euler 3-13 frame of reference for any part of the multi-body system are

$$
\left\{q_{j}\right\}_{j=1 \rightarrow 6}^{\mathrm{T}}=\{x, y, z, \psi, \theta, \varphi\}
$$

denotes the rigid body degrees of freedom, and

$$
\left\{q_{j}\right\}_{j=6 \rightarrow 6+n_{m}}^{\mathrm{T}}=\left\{x, y, z, \psi, \theta, \varphi, q_{m}\right\}
$$

denotes the flexible body degrees of freedom.

The desired modal responses are included in the form of suitably reduced mass and stiffness matrices into Lagrangian dynamics analysis, and thus the elastodynamic behaviour of the system can be simulated under given excitations such as combustion gas force and load torque. More details can be found in reference [15].

Applied forces, aside from combustion gas force and load torque, are provided by the reaction and friction from all the contact conjunctions. These are used in the core multi-body dynamics model in the environment of ADAMS. The tribological conjunctions are provided as user defined subroutines linked to ADAMS. Other important parameters, such as lubricant film thickness, its rheological state, and generated contact pressure distributions are integrated with ADAMS environment as user defined request subroutines.

\subsection{Tribological contact conjunctions}

\subsubsection{Main journal bearing reactions}

A single-cylinder four-stroke variable compression gasoline E6 Ricardo engine with $75 \mathrm{~mm}$ bore, and a $120 \mathrm{~mm}$ stroke is used for the experimentation. This produces a maximum of $13 \mathrm{Bhp}$ at $3000 \mathrm{r} / \mathrm{min}$. The tests were carried out at a torque of $40 \mathrm{Nm}$ at a speed of $1800 \mathrm{r} / \mathrm{min}$.

There are many ways to represent the main journalbearing reactions. A realistic approach, yielding an analytical solution is to use the short bearing approximation with half-Sommerfeld boundary condition by Kirk and Gunter [7], who considered purely hydrodynamic conditions. This is appropriate for the E6 engine investigated here, where the speed of rotation is $1800 \mathrm{r} / \mathrm{min}$ and the thickness of the journal bearings' bushings is $5 \mathrm{~mm}$. The tribological models used do not apply to thin shell or overlay bearings. Some engine bearings are furnished with soft overlays to encourage elastohydrodynamic regime of lubrication through localized deformation of the bearing bushing. In such cases, an iterative procedure is required [16].

With the known geometry, kinematics, and lubricant rheology, solutions for the Reynolds equation can be sought considering short-width bearing approximation as $2 r_{j} / \ell \geqslant 2$ for the main crankshaft support bearings. This gives the pressure distribution around the journal as a function of the eccentricity ratio $[7,17]$

$$
p=\frac{3 u_{j} \eta_{0} \varepsilon}{r_{j} c}\left(\frac{L^{2}}{4}-y^{2}\right) \frac{\sin \alpha}{(1+\varepsilon \cos \alpha)^{3}}
$$

where the eccentricity ratio is defined as $\varepsilon=e / c$.

This equation shows that a parabolic function governs the axial variation of pressure, whereas the geometric film function dictates its circumferential distribution. Generally, mineral oils contain 8-12 per cent of dissolved air. Whenever the pressure falls below the saturation pressure, the dissolved air evolves from the solution [18]. Therefore, sub-ambient pressures predicted by equation (2) are ignored and it is assumed that the positive pressure region occupies $\alpha=0$ to $\alpha=\pi$, carrying the applied load.

The only unknowns required are the eccentricity $e$ of the journal centre from the geometric centre of the bushing (provided by the dynamics analysis in each step of time) and the angular velocity $\omega$. The loadcarrying capacity can be calculated by integrating the pressure distribution around the circumference (see Fig. 3). As such the components of the load vector along $W_{x}$ and perpendicular $W_{z}$ to the line of centres are obtained as [19]

$$
\begin{aligned}
& W_{z}=\frac{u_{j} \eta_{0} L^{3}}{4 c^{2}} \frac{\pi \varepsilon}{\left(1-\varepsilon^{2}\right)^{3 / 2}} \\
& W_{x}=\frac{u_{j} \eta_{0} L^{3}}{c^{2}} \frac{\varepsilon^{2}}{\left(1-\varepsilon^{2}\right)^{2}}
\end{aligned}
$$

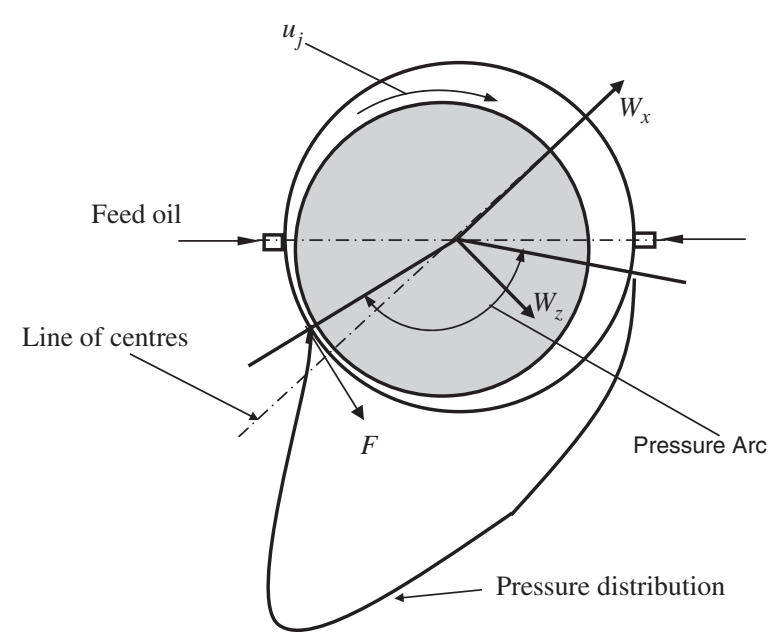

Fig. 3 Forces applied to the journal 


\subsubsection{Friction in journal bearings}

Friction in the engine bearing conjunction with the short-bearing approximation is given by the wellknown Petrov friction $[\mathbf{1 9}, \mathbf{2 0}]$

$$
F=\frac{-2 \pi \eta u_{j} r_{j} L}{c} \frac{1}{\sqrt{1-\varepsilon^{2}}}
$$

\subsubsection{Piston compression ring-cylinder liner conjunction}

For the case of a piston ring with small face-width and long perimeter ( $\pi D, D$ being the bore diameter), such that the ratio of its width to bore diameter is typically of the order of 0.01 or less, one may assume that pressure variation along its width is far more significant than along the circumference. Thus, many investigators have used the elastic line contact analysis approach such as a roller on a semi-infinite elastic half-space to obtain an analytic solution for a thin rectangular footprint strip shape, such as that obtained in reference $[\mathbf{2 1}]$. The approach also assumes only partial conformance of ring axial geometry to the surface of the bore or liner. The full Reynolds equation can now be simplified using long line contact assumption, where there is no leakage along the sides [22]. Thus, the pressure variation along the ring face-width can be formulated, applying Reynolds or Swift-Steiber exit boundary conditions. This determines the point of film rupture. Therefore, the pressure variation along the face-width of the ring becomes

$$
\begin{aligned}
p^{*}= & \frac{1}{8} \bar{x}-\frac{1}{32} \sin 4 \bar{x}-\tan ^{2} \bar{x}_{\mathrm{r}}\left(\frac{3}{8} \bar{x}+\frac{1}{4} \sin 2 \bar{x}\right. \\
& \left.+\frac{1}{32} \sin 4 \bar{x}\right)+\frac{4 w_{\mathrm{s}}^{*}}{\sqrt{2 h_{m}^{*}}}\left[-\frac{3}{32}-\frac{1}{8} \cos 2 \bar{x}-\frac{1}{32}\right. \\
& \left.\times \cos 4 \bar{x}-\tan \bar{x}_{\mathrm{r}}\left(\frac{3}{8} \bar{x}+\frac{1}{4} \sin 2 \bar{x}+\frac{1}{32} \sin 4 \bar{x}\right)\right] \\
& +\frac{\pi}{16}\left(1-3 \tan ^{2} \bar{x}_{\mathrm{r}}-\frac{12 w_{\mathrm{s}}^{*}}{\sqrt{2 h_{m}^{*}}} \tan \bar{x}_{\mathrm{r}}\right)
\end{aligned}
$$

where film rupture point $x_{\mathrm{r}}$ can be found from [22]

$$
\begin{aligned}
& \frac{1}{8} \bar{x}_{\mathrm{r}}-\frac{1}{32} \sin 4 \bar{x}_{\mathrm{r}}-\tan ^{2} \bar{x}_{\mathrm{r}}\left(\frac{3}{8} \bar{x}_{\mathrm{r}}+\frac{1}{4} \sin 2 \bar{x}_{\mathrm{r}}\right. \\
& \left.+\frac{1}{32} \sin 4 \bar{x}_{\mathrm{r}}\right)+\frac{4 w_{\mathrm{s}}^{*}}{\sqrt{2 h_{m}^{*}}}\left[-\frac{3}{32}-\frac{1}{8} \cos 2 \bar{x}_{\mathrm{r}}-\frac{1}{32}\right. \\
& \left.\quad \times \cos 4 \bar{x}_{\mathrm{r}}-\tan \bar{x}_{\mathrm{r}}\left(\frac{3}{8} \bar{x}_{\mathrm{r}}+\frac{1}{4} \sin 2 \bar{x}_{\mathrm{r}}+\frac{1}{32} \sin 4 \bar{x}_{\mathrm{r}}\right)\right] \\
& +\frac{\pi}{16}\left(1-3 \tan ^{2} \bar{x}_{\mathrm{r}}-\frac{12 w_{\mathrm{s}}^{*}}{\sqrt{2 h_{m}^{*}}} \tan \bar{x}_{\mathrm{r}}\right)=0
\end{aligned}
$$

The maximum predicted lubricant pressure inside the contact is insufficient, either deforming the contiguous surfaces or promoting piezo-viscous action of the lubricant. Therefore, the hydrodynamic analysis with iso-viscous lubricant behaviour suffices.

\subsubsection{Piston skirt-cylinder wall contact reactions}

The behaviour of the piston inside the cylinder can be assumed to be rigid with a few possible modes as noted by Haddad and Tian [23]. These configurations allow the piston skirt to form a wedge with the cylinder wall to a varying degree of conformity at all times. If contact kinematics and piston alignment are known, then the lubricant film thickness and consequently the contact forces with thrust and anti-thrust sides may be calculated. Unlike the piston compression ring conjunction, the wedge effect of the piston confines the lubricant pressure distribution largely to its edges, thus the contact length along the piston is selected based on extreme operating conditions. Figure 4 shows the pressure variation for such conditions. The contact domain for the lubrication analysis is restricted to a quarter of the piston perimeter (length $58 \mathrm{~mm}$ ), symmetric around the contact point and for a length of $20 \mathrm{~mm}$ along the piston skirt (Fig. 5). This leaves a width-to-length ratio of 2.9, which is well in excess of the limiting value of 2 for it to be considered as a long bearing approximation $[\mathbf{1 8}, \mathbf{2 4}]$.

\subsubsection{Fictional analysis in piston conjunction}

If a machine element is adequately designed with a coherent lubricant film, the contacting surfaces are entirely kept apart. The conjunctional friction is due to the viscous shear of the lubricant film, which is usually quite low. Conversely, when the film thickness is insufficient, asperity interactions can also occur. This can lead to increased frictional losses, also promoting wear. The overall friction is then a result of the combined viscous action of the lubricant and boundary interactions. The regime of lubrication is termed mixed.

The regime of lubrication can be surmised, using the Stribeck's oil film parameter $[\mathbf{1 8}], \lambda=h / \sigma$. If this parameter is greater than 3 , then friction is due to viscous action alone, such that

$$
F_{\mathrm{v}}=\frac{\eta \Delta u}{h} A
$$

where $\Delta u$ is the speed of sliding. Mixed regime occurs, when $1<\lambda<3$, where both boundary and viscous frictions contribute to the total friction. Boundary friction is due to asperity interactions; the definition of friction originally expounded by Amontons. Greenwood and Tripp [25] proposed a model based on Gaussian distribution of asperities on the counterfaces, which simplifies to

$$
F_{\mathrm{b}}=\tau_{\mathrm{e}} A_{\mathrm{a}}+c_{\mathrm{pb}} P_{\mathrm{a}}
$$




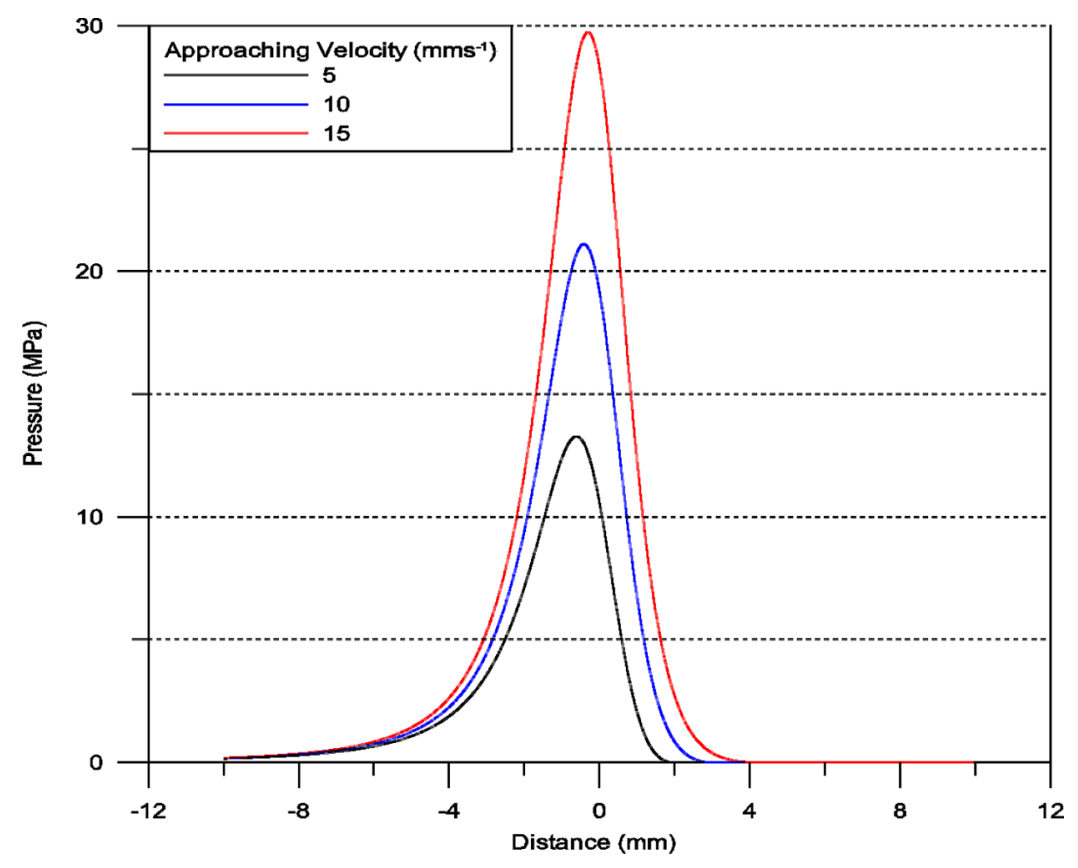

Fig. 4 Piston edge pressure variation along the contact

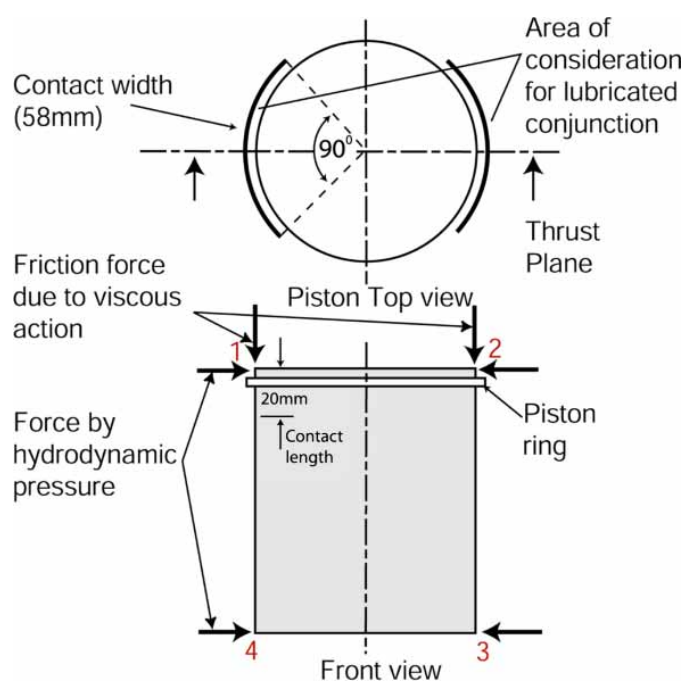

Fig. 5 Contact domain for the piston skirt-cylinder wall analysis

where $\tau_{\mathrm{e}} \approx 2 \mathrm{MPa}$ is the Eyring [26] shear stress for engine oil, $A_{\mathrm{a}}$ the total area of asperity tip pairs in contact and $c_{\mathrm{pb}} \approx 0.17$ according to Johnson [27] and Teodorescu et al. [28]. When asperity interactions take place, the lubricant film is quite thin and its behaviour (in parts, i.e. at the asperity tips) is assumed to be non-Newtonian. Thus, the Eyring shear stress defines the limiting value, where non-Newtonian behaviour occurs [19]. For, $\tau \leqslant \tau_{\mathrm{e}}(=2 \mathrm{MPa})$, the Newtonian behaviour prevails within the contact and the shear stress becomes

$$
\tau=\frac{\eta \Delta u}{h}
$$

However, if the value of shear stress exceeds the Eyring value, then the non-Newtonian behaviour prevails

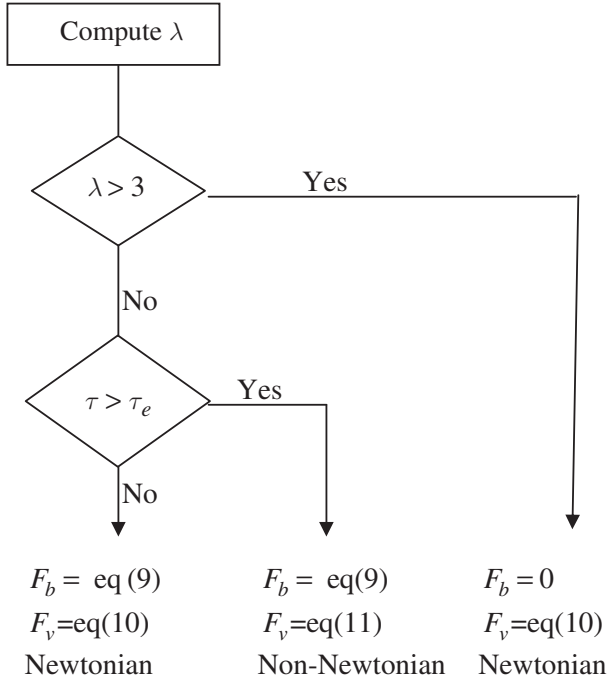

Fig. 6 Flowchart for friction force calculation

and the shear stress is determined by the rheological properties of the oil

$$
\tau=\tau_{0}+\gamma_{\mathrm{s}}\left(\frac{P-P_{\mathrm{a}}}{A_{\mathrm{h}}}\right)
$$

where $\gamma_{\mathrm{s}}$ is the slope of the limiting shear stresspressure relationship. This can be approximated to a mean sliding velocity $(\Delta u / 2)$ of the contact (speed of entraining motion of the lubricant film). The flowchart for the lubrication analysis is given in Fig. 6 .

\subsubsection{Temperature effects in lubricated contacts}

The aforementioned analytical methods are based on the assumption that isothermal conditions are present 
in the tribological contacts. However, the temperature of the lubricant rises from that of its bulk value, reducing its viscosity, which in turn decreases the film thickness. In conjunctions with lower pressures and larger clearance values (and particularly at lower shear rates), the temperature rise is less pronounced and its effects may be neglected, at least as a first approximation. However, in less conforming conjunctions and at high shear rates, such as the case of piston ringto-cylinder liner contact, the temperature rise, and its effect on the lubricant viscous behaviour cannot be ignored. Thus, the Reynolds pressure variation in the contact changes, while altering the reaction force. Prediction of temperature rise in such lubricated contacts is an important contribution to the process of engineering design. The conservation of energy at a point in the lubricant film is the fundamental equation necessary for this prediction. Assuming that there is no other external source of heat, the pressure along the film thickness is constant under steady state conditions. Considering the fluid flow only in the direction of sliding ( $x$-direction), then the two-dimensional (2D) energy equation for the contact is given by reference [17] as

$$
\underbrace{v_{\mathrm{e}} \Delta u \theta\left(\frac{\partial p}{\partial x}\right)}_{\begin{array}{c}
\text { compressive } \\
\text { heating }
\end{array}}+\underbrace{\eta\left(\frac{\partial \Delta u}{\partial z}\right)^{2}}_{\begin{array}{c}
\text { viscous } \\
\text { heating }
\end{array}}=\underbrace{\rho v_{x} C_{\mathrm{p}}\left(\frac{\partial \theta}{\partial x}\right)}_{\begin{array}{c}
\text { convection } \\
\text { cooling }
\end{array}}-\underbrace{k_{\mathrm{c}}\left(\frac{\partial^{2} \theta}{\partial z^{2}}\right)}_{\begin{array}{c}
\text { conduction } \\
\text { cooling }
\end{array}}
$$

The heat is generated due to compressive action (at high pressures), as well as viscous action in the contact. This is then dissipated to the environment by convection or by conduction cooling. Depending on the situation, the terms in equation (11) contribute differently to the heat balance. Under hydrodynamic conditions, compressive heating is slight compared with that due to viscous shear [17]. Therefore, it is possible to neglect the effect of compressive heating, while it is not possible to make such an assumption under elastohydrodynamic conditions. Assuming that hydrodynamic conditions are prevalent in the contact such as piston ring to cylinder wall, the effect due to compressive heating has been neglected here, thus

$$
\eta\left(\frac{\partial \Delta u}{\partial z}\right)^{2}=\rho \Delta u C_{\mathrm{p}}\left(\frac{\partial \theta}{\partial x}\right)-k_{\mathrm{c}}\left(\frac{\partial^{2} \theta}{\partial z^{2}}\right)
$$

The whole contact domain was taken into consideration and assuming that the temperature gradient across the film varies linearly, then

$$
\frac{\eta \Delta u^{2} B}{h}=\frac{\rho \Delta u C_{\mathrm{p}} h \Delta \theta}{4}+\frac{k_{\mathrm{c}}(\Delta \theta) B}{2 h}
$$

This equation can be used to find the temperature rise $\Delta \theta$ and the effective average contact temperature $\theta_{\mathrm{e}}$ can be calculated using a relaxation method such as

$$
\theta_{\mathrm{e}}=\theta_{1}+k_{\mathrm{e}} \Delta \theta
$$

where $\theta_{1}$ is the inlet temperature and $k_{\mathrm{e}}=0.5$ for this case. Then, the effective viscosity, corresponding to the effective contact temperature $\theta_{\mathrm{e}}$, can be calculated using the Vogel equation

$$
\ln \eta_{\mathrm{e}}=-1.845+\left(\frac{700.81}{\Theta_{\mathrm{e}}-203}\right)
$$

where $\Theta_{\mathrm{e}}=\theta_{\mathrm{e}}+273$.

The iterative procedure continues until a convergence criterion is met with the required accuracy. The above procedure is followed for the calculation of effective lubricant viscosity in the piston ring-cylinder wall contact.

\section{RESULTS AND DISCUSSION}

A two-beam laser vibrometer was used to measure the transverse velocity (Fig. 7) of the flywheel edge. This is termed nodding motion (Fig. 1) [15]. The corresponding numerically predicted results are shown in Fig. 8. As it can be seen, the two sets of results agree quite well. However, the amplitude of oscillation of the measured signal is slightly larger. This may be attributed to the engine block flexibility, which is not taken into account in the numerical model. Figures 9 and 10 show the FFT spectra of the results in Figs 7 and 8, respectively. These also show good conformance in terms of spectral contents. The differences in particular spectral contributions are because of the various subsystems (valve train, timing gears, oil pump, etc.), which are not included in the model. Both sets of results show the inherent unbalanced nature of the single-cylinder engines, with vibration signature of the four-stroke process [1]. It should also be noted that some complex tribological conjunctions, such as the big-end and small-end bearings are simply represented by basic rigid constraint functions in the current model. As a result, the combustion gas force does not excite the lower frequency crankshaft bending modes, as could be the case in an actual engine. This explains the differences between the experimental measurements and numerical predictions above the third engine order.

The approach velocity of the journal surface towards the bearing bushing introduces a squeeze-film action. Figure 11 shows the bearing centre velocity variation in the radial direction. This reveals that the hydrodynamic pressure is dominated by the squeeze-film action at the dead centres (every $180^{\circ}$ crank angle). Once the reaction force passes through these peak values, the two contacting bodies begin to separate. The mechanism of lubricant film formation is then dominated by the entraining motion of the lubricant 


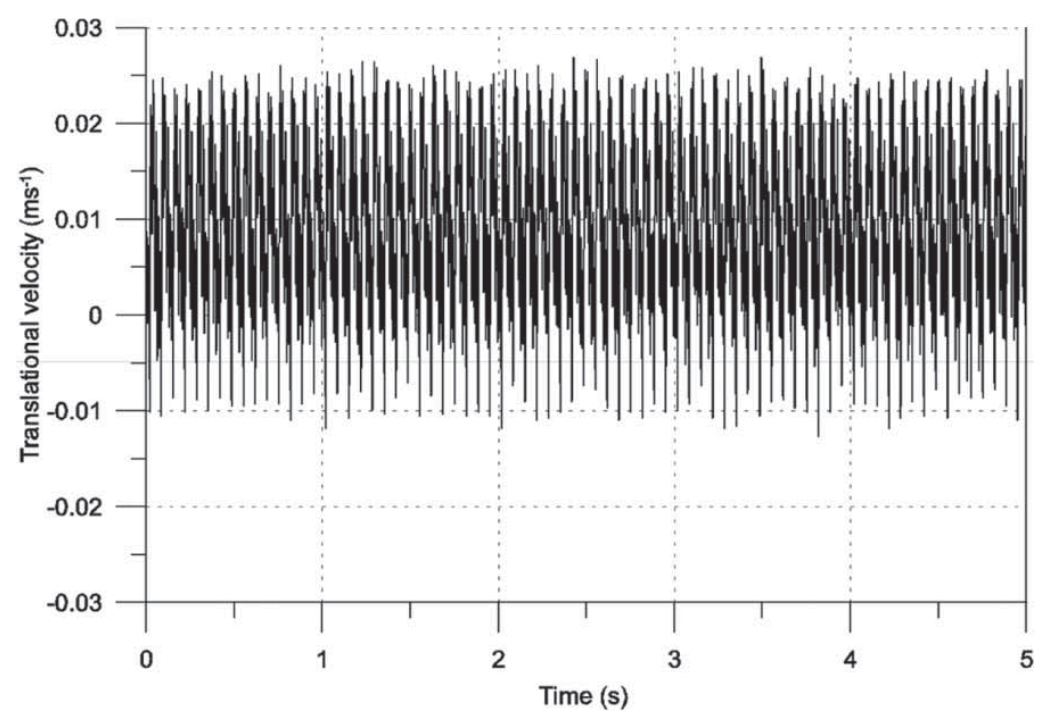

Fig. 7 Time history of the experimentally measured flywheel nodding velocity

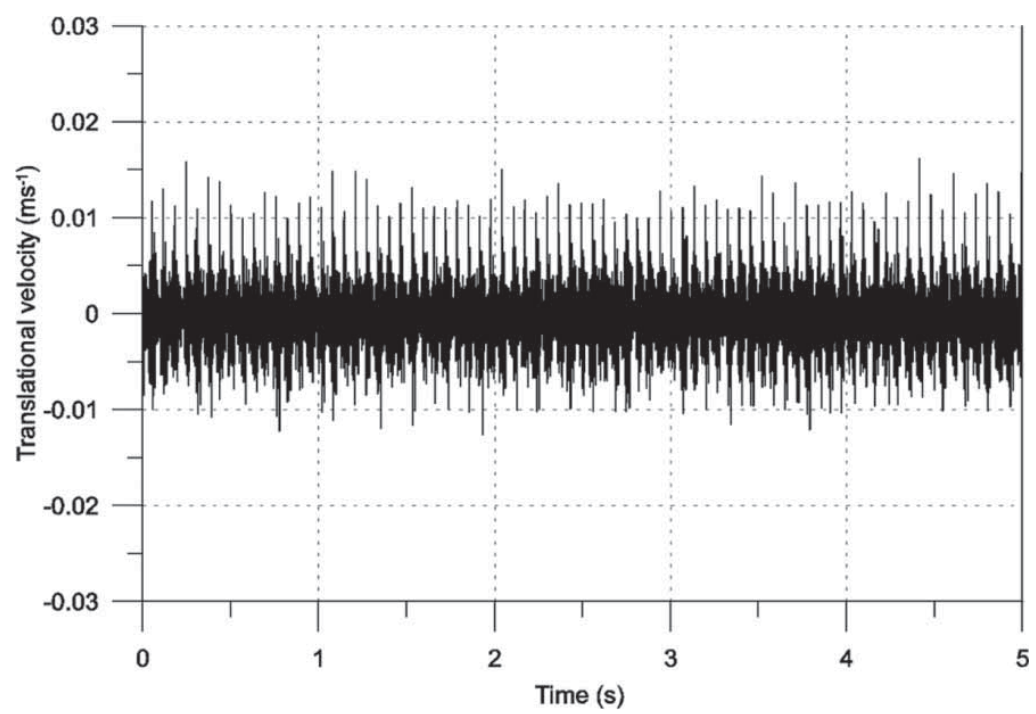

Fig. 8 Time history of the numerically predicted flywheel nodding velocity

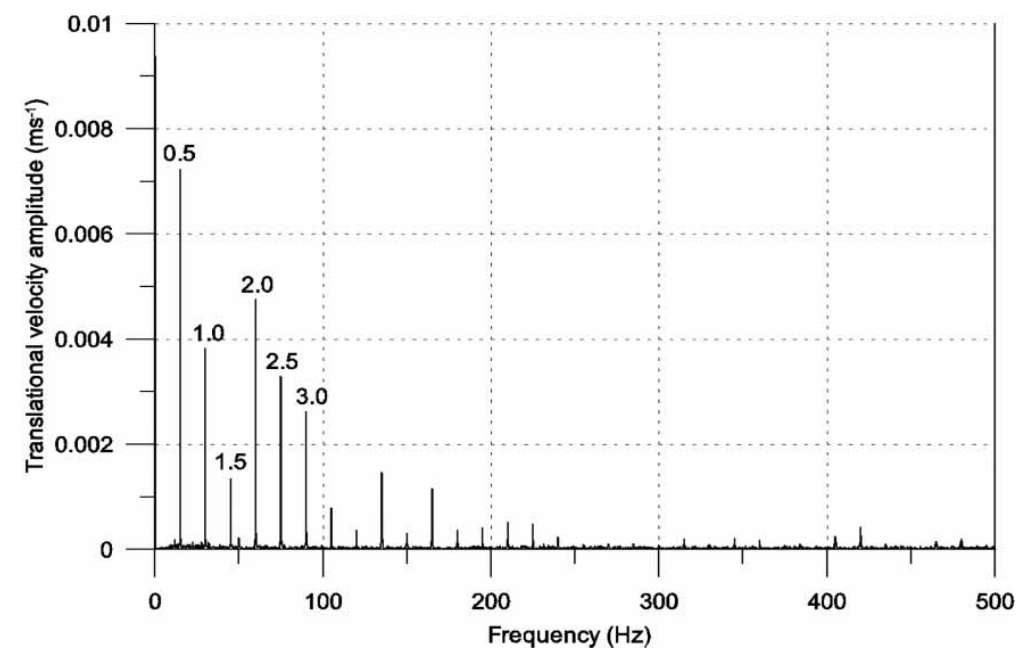

Fig. 9 Spectral content of the experimentally measured flywheel nodding motion 


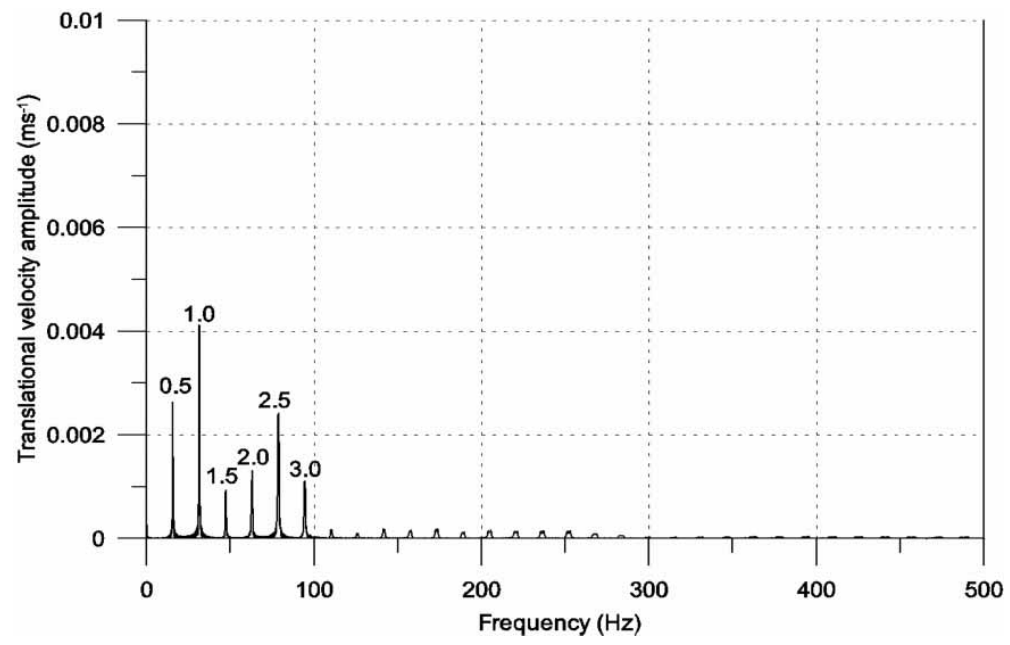

Fig. 10 Spectral content of the numerically predicted flywheel nodding velocity

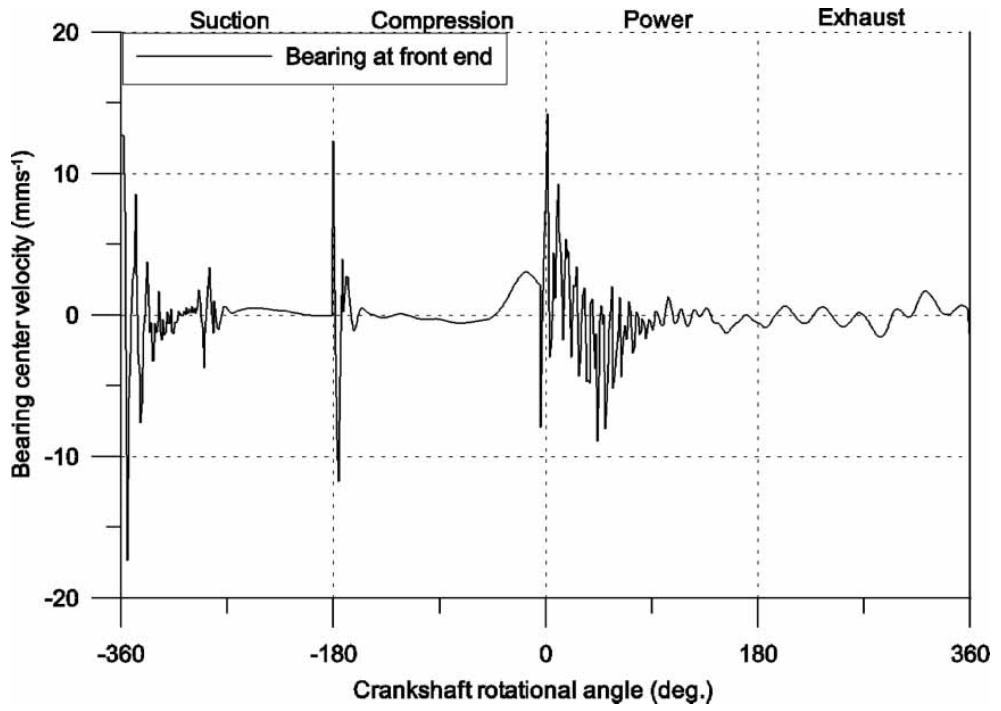

Fig. 11 Radial bearing centre velocity during the four-stroke cycle

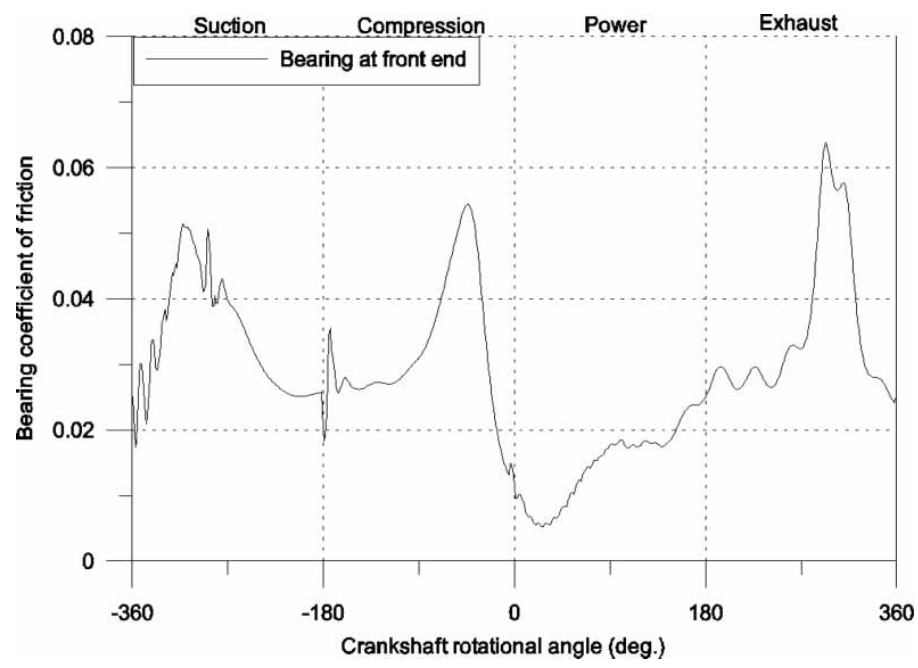

Fig. 12 Variation of coefficient of friction in the bearing conjunction 


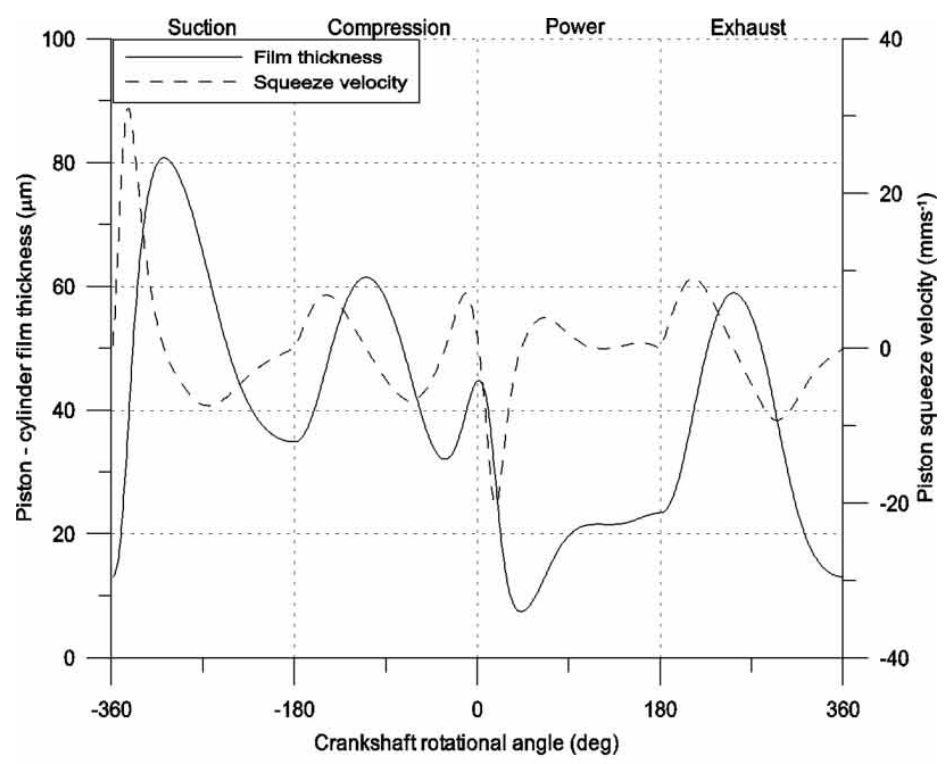

(a)

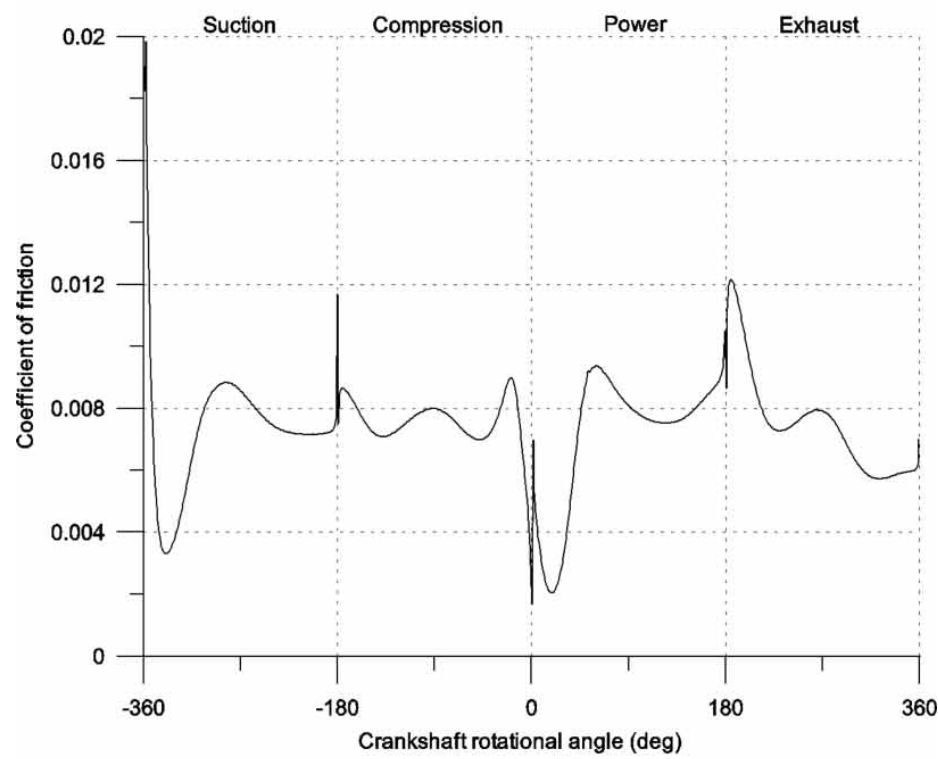

(b)

Fig. 13 (a) Film thickness and squeeze velocity variation at thrust side (at piston position 2 shown in Fig. 4) and (b) variation of coefficient of friction at the thrust side (at piston position 2 shown in Fig. 4)

into the contact (pure entraining motion occurs when the radial approach velocity diminishes altogether). The above points are further augmented by the coefficient of friction variation in the bearing, shown in Fig. 12. Under hydrodynamic conditions, the reaction force in the journal bearing is dominated by the lubricant entraining motion. Before the bearing is subjected to its peak load, the hydrodynamic pressure is dominated by the squeeze-film action, and thus the coefficient of friction is reduced. Just past the peak load, the two contacting bodies begin to depart, and thus, more lubricant is drawn into the contact, increasing the coefficient of friction due to viscous shear. Furthermore, the angle between the line of centres and the resultant bearing load, termed the attitude angle tends to decrease with an increase in eccentricity (which is expected, as found analytically by Cameron [20] and Pinkus and Sternlicht [24]). Hence, the attitude angle reduces with greater eccentricity ratio $\varepsilon$ and the bearing operates more stably [19]. With decreased $\varepsilon$, the reaction force component perpendicular to the line of centres increases the friction torque and unstable whirl can become a problem. 


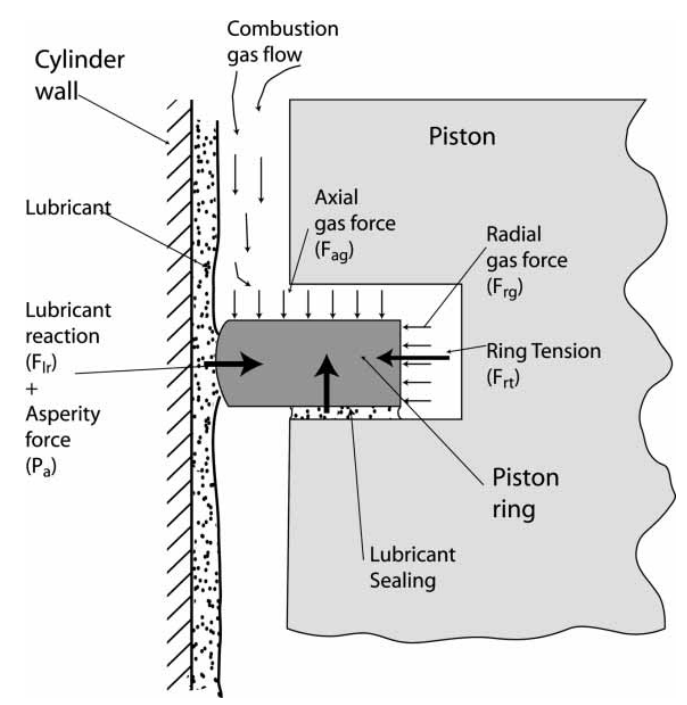

Fig. 14 Ring motions relative to the groove

Figure 13(a) shows the variations of squeeze velocity and lubricant film thickness on the piston thrust side in the skirt conjunction. As it can be seen, the maximum squeeze velocity occurs a few degrees after the top dead centre (TDC) in the power stroke. Also, as the film thickness is reduced the squeeze velocity contributes more to the load-carrying capacity. With increased speed of entraining motion, viscous shear causes a rise in friction (Fig. 13(b)). At maximum combustion, past the TDC, the coefficient of friction is at its lowest value (Fig. 13(b)) as the load is dominated by the squeeze-film action rather than fluid entrainment into the contact. At the beginning of the suction stroke, the rate of separation is at its maximum (Fig. 13(a)), while the coefficient of friction is reduced further (Fig. 13(b)). At this point, the thrust force almost diminishes, causing a clearance of $60-80 \mu \mathrm{m}$. This may result in the loss of the lubricant film, particularly with low speeds of entraining motion. In all cases, the relatively low coefficient of friction indicates the dominance of viscous shear over asperity interactions.

As already shown by film thickness in the skirt conjunction, particularly for the E6 engine, a sufficient film thickness inhibits direct surface interactions. This is not usually the case for the ring pack, particularly for the compression ring, considered in this analysis. A majority of the reported investigations have focussed on piston ring lubrication, independent of a multibody dynamics analysis of the system as a whole. This approach has the repercussion of ignoring the secondary motion due to the clearance gap between the piston ring and the groove. Owing to this clearance, the ring resides on the lower groove surface during the upward motion of the piston, and rests on the upper groove surface during the down stroke motion (Fig. 14). Therefore, in the former, the inner surface of the ring is subjected to the combustion chamber pressure, while in the latter it is subjected to the crankcase pressure. The force due to ring tension and inner ring pressure is balanced by the lubricant reaction force acting on the ring face-cylinder wall interface. Figure 15 shows the variation of the reaction force at the piston ring face in contact with the cylinder wall. This comprises the asperity load and the hydrodynamic viscous reaction. During the suction and power strokes, the piston moves downwards. Therefore, the inner ring face is subjected to the crankcase pressure, which is assumed to be almost the atmospheric pressure. Therefore, the reaction force is dominated by the outward ring tension, which is assumed to be constant in this analysis. Hence, almost a constant

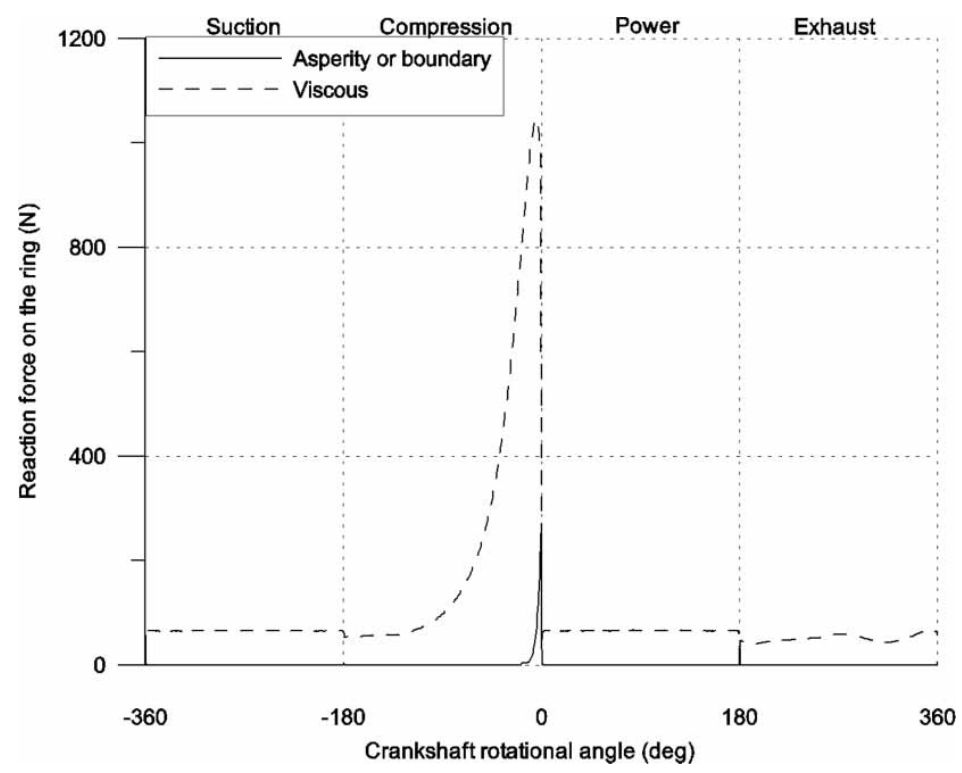

Fig. 15 Reaction force variation in the piston ring-cylinder wall conjunction 


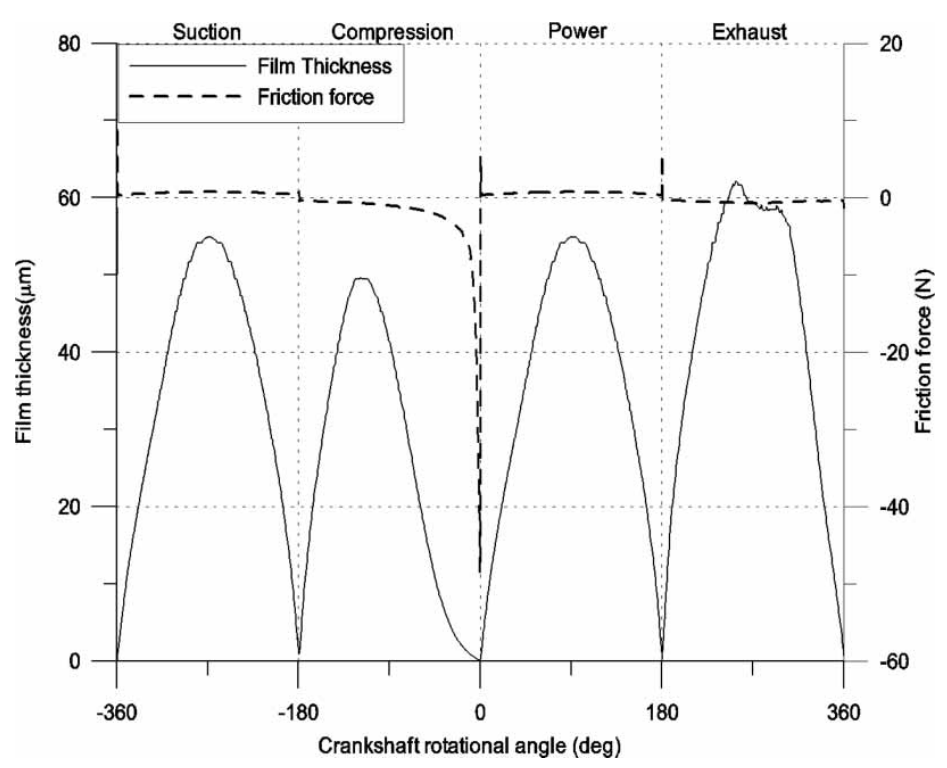

Fig. 16 Variation of film thickness and friction force in the piston ring-cylinder wall conjunction

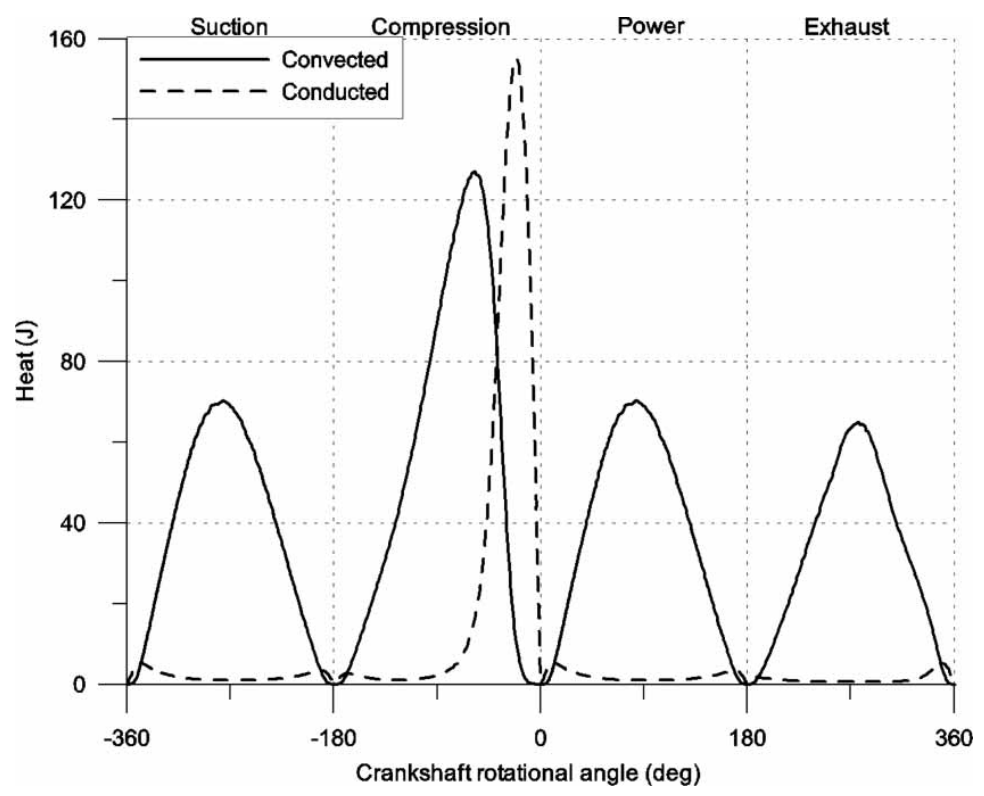

Fig. 17 Modes of heat dessipation from the piston ring-cylinder wall conjunction

reaction force can be seen during these two strokes. During compression and exhaust strokes, the piston moves upwards, while exposing the face of the inner ring to the combustion chamber pressure (Fig. 14). Therefore, during these two strokes, the reaction force is augmented by the gas pressure and ring tension, and consequently, a higher ring force is observed. In particular, in the vicinity of the TDC, the diminished film thickness clearly gives rise to a larger proportion of the contact force being carried by asperity interactions.

Figure 16 shows the minimum film thickness variation and friction at the ring face-to-cylinder wall contact for the four-stroke combustion cycle. The film thickness is sufficiently large, particularly at midspan to result in relatively low friction. However, at all reversals (dead centres), the film is reduced and the resulting mixed regime of lubrication causes an increase in friction. This is more significant at the TDC in transition from compression stroke to power stroke. Clearly, many such reversals under normal operating conditions account for the significant parasitic losses that ensue from compression ring-to-cylinder bore contact. The situation deteriorates as the rising contact temperatures result in shear thinning of the lubricant film.

Figure 17 shows the heat dissipation due to convection through lubricant action and conduction through 


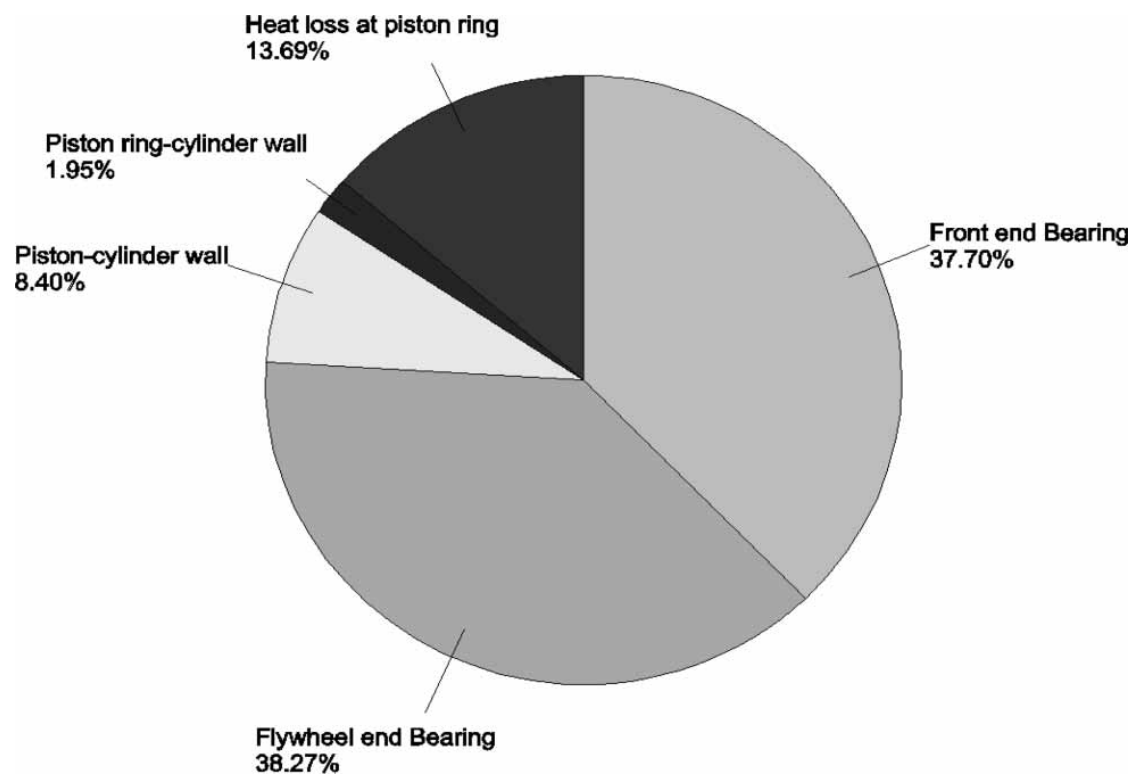

Fig. 18 Percentage energy loss in the engine model

the bounding solid surfaces in contact. Whenever thicker films occur during the cycle, convection cooling becomes significant and the lubricant film carries more of the heat away from the contact. Therefore, a higher contribution from convection cooling can be seen at mid-span of each stroke, where the film thickness is relatively large (note that the clearance is $100 \mu \mathrm{m})$. At the dead centres, with the dominance of boundary lubrication, the film is very thin. This is further exacerbated with the reduced entraining velocity. Thus, conduction cooling becomes more significant.

Changes in viscosity, kinematics, and degree of conformity of the contact affect the frictional characteristics. Thus, with known frictional data, it is possible to estimate the engine losses affecting the output power. Figure 18 shows the percentage of energy losses for the examined E6 conjunctions of the engine. It must be noted that there are other components such as the cam-tappet conjunction, big-end and small-end bearings, timing gears, oil, water pumps, etc., that contribute to the engine losses which have not been considered in this model. Thus, the proportions of losses attributed to the various considered conjunctions are not true of their overall contributions in terms of the entire engine mechanical losses.

\subsection{Effect of crankshaft offset}

The validated model can be used as a design tool to examine a series of what-if scenarios. Of particular interest is the effect of crankshaft offset, which is carried out to ensure adherence of the piston to the major thrust side, thus reducing its side to side motions and subsequent problems due to loss of lubrication and piston slapping action. The side force acting on the piston diminishes at the TDC, if the crankshaft is in line with the piston axis. This makes the connecting rod and the crank-throw reside on a vertical line. However, a few crank degrees prior to the TDC, a net resultant force acts towards the anti-thrust side of the cylinder wall. This force reverses in direction just a few degrees after the TDC. Such a sudden force variation results in the piston slapping action. The sudden rise in the side force can also lead to depletion of the lubricant film. Offsetting the crankshaft towards the major thrust side is expected to smoothen this effect. It must be noted that a change in the crankshaft position (offsetting) alters the orientation of the piston crankshaft assembly. Since the numerical model is parameterized, such a modification can be easily accommodated.

Figures 19(a) and (b) show the frictional variation of the piston skirt-to-cylinder wall contact for thrust and anti-thrust sides, respectively. The regime of lubrication remains hydrodynamic throughout the cycle except close to the dead centres [15]. During compression and exhaust strokes, the piston moves upwards and friction acts downwards. However, the absolute maximum friction force exists during the power stroke and it decreases with an increase in crankshaft offset. As shown in Fig. 20, the crank offset induces higher squeeze-film action, $w_{\mathrm{s}}^{*}$, which in the case of the thrust side increases the load-carrying capacity of the contact (for the same side force a greater lubricant film is attained), thus reducing the incidents of asperity interactions at dead centres. Similar trend was observed by Ragot and Rebbert [29] in their experiments. Note that the given friction force in the figure is only for piston skirt to bore contact and it does not include that of the piston rings. 


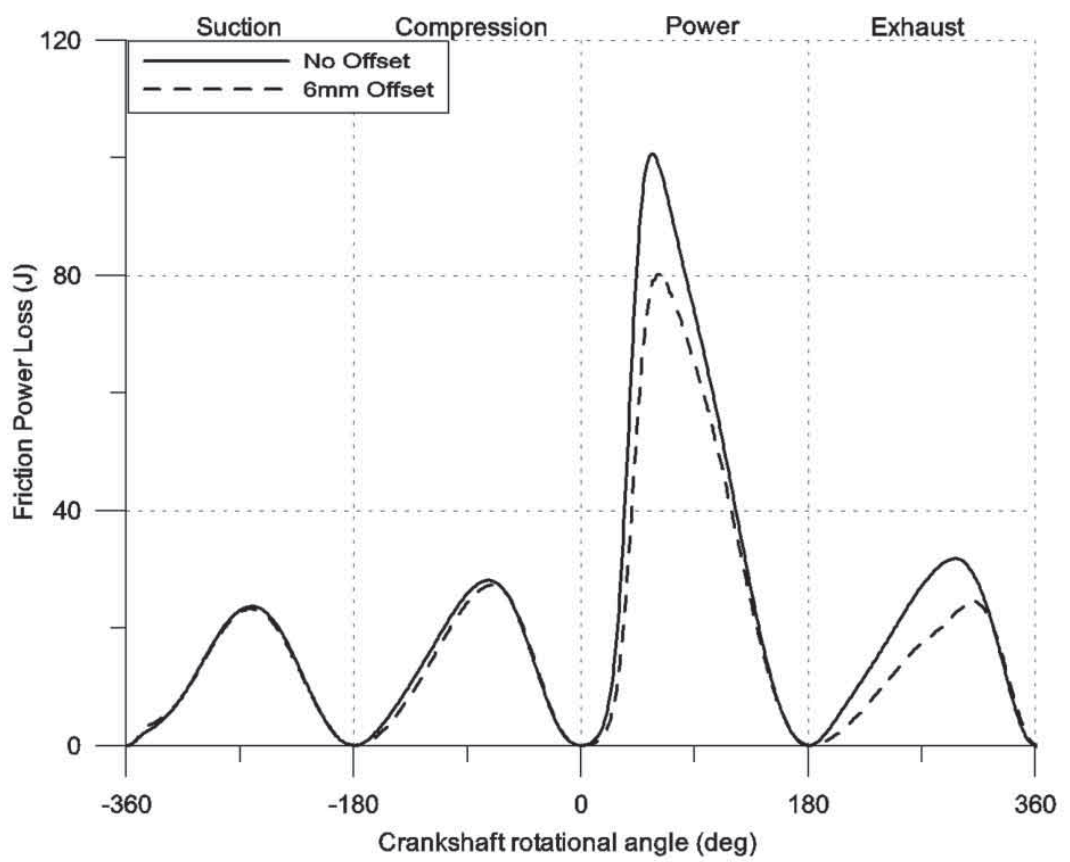

(a) Thrust side

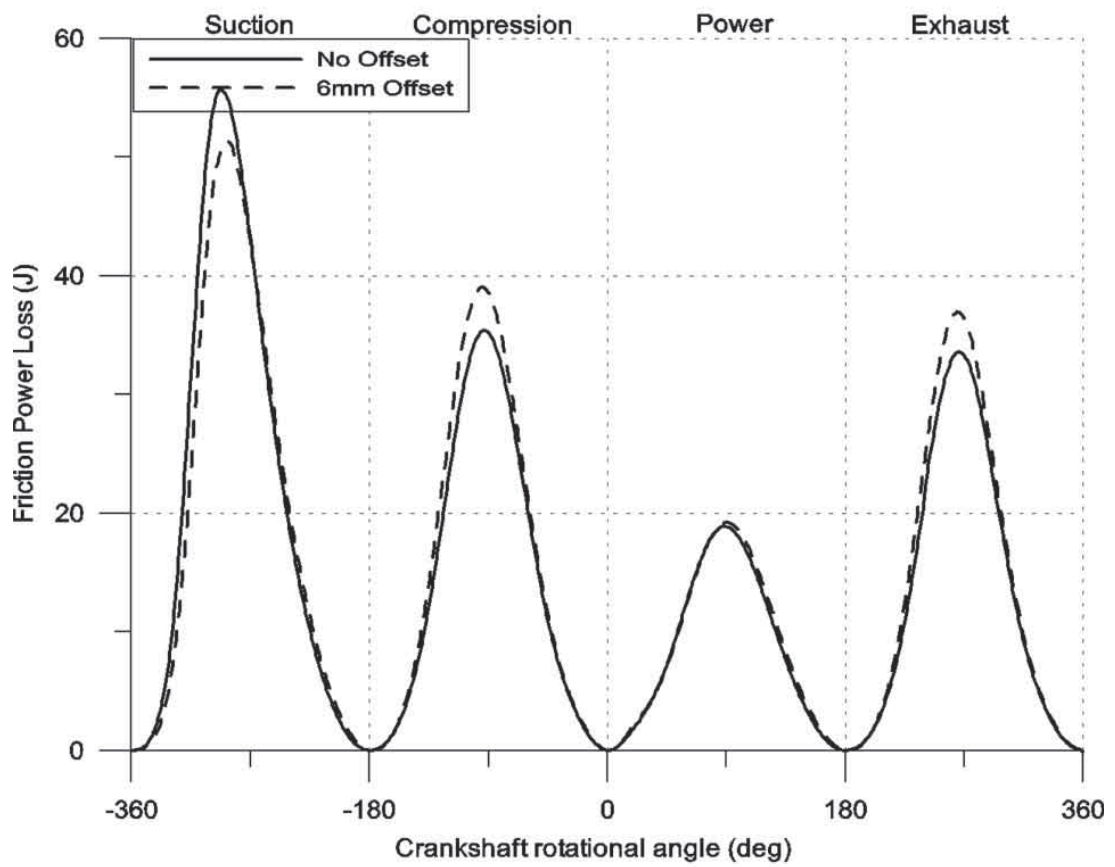

(b) Anti thrust side

Fig. 19 Frictional power loss at piston skirt to cylinder wall contact with and without crankshaft offset

The results in Fig. 19 show that offsetting the crankshaft reduces the frictional losses $\int F \Delta u$ over the cycle. The overall reduction in the parasitic losses are 4.5 per cent, where the gain on the thrust side is 10 per cent $\left(w_{\mathrm{s}}^{*}<0\right.$, enhanced squeeze film action) and the increased frictional losses on the anti-thrust side is only 3 per cent $\left(w_{\mathrm{s}}^{*}>0\right.$, separation, reduced load carrying capacity).
Figure 21 shows that there is little change in the main bearing friction due to crankshaft offset. The main bearing reaction force is mainly due to combustion gas force, inertial forces, and connecting rod force. The friction force is very small compared with the combustion gas force and inertial forces. Therefore, a reduction in piston friction does not significantly influence bearing friction forces. 


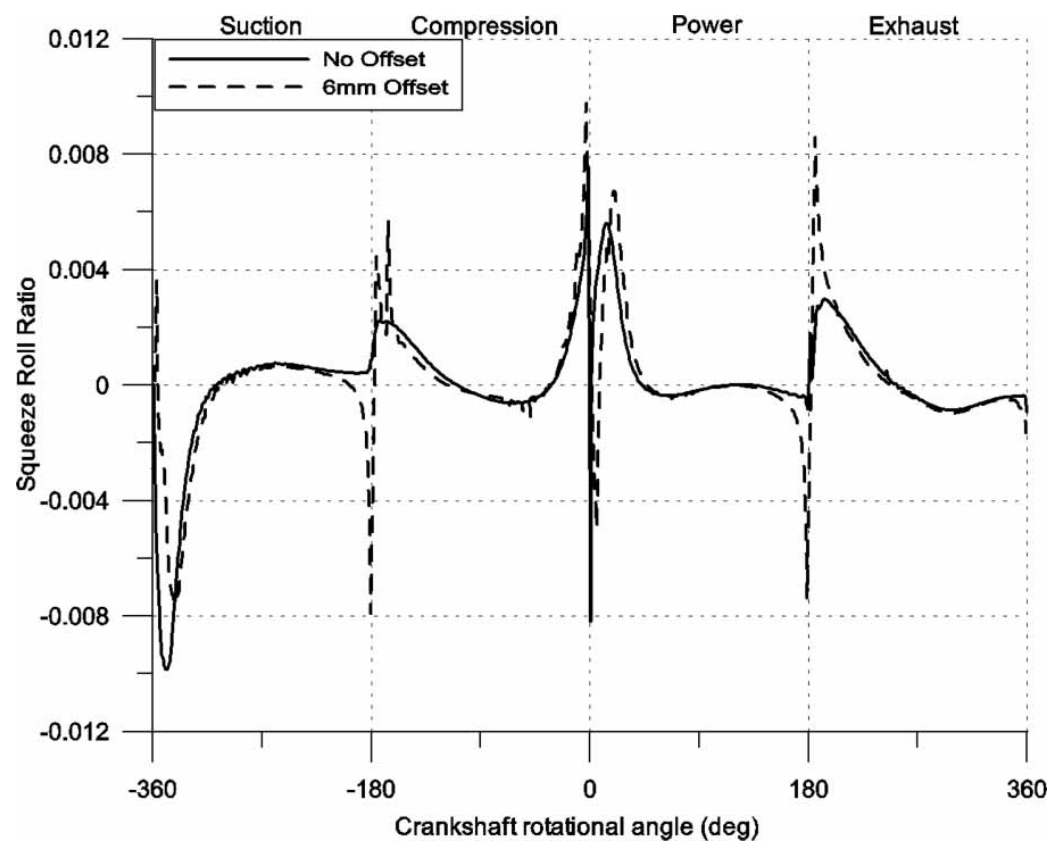

Fig. 20 Squeeze-roll ratio at piston skirt to sleeve contact with and without crankshaft offset

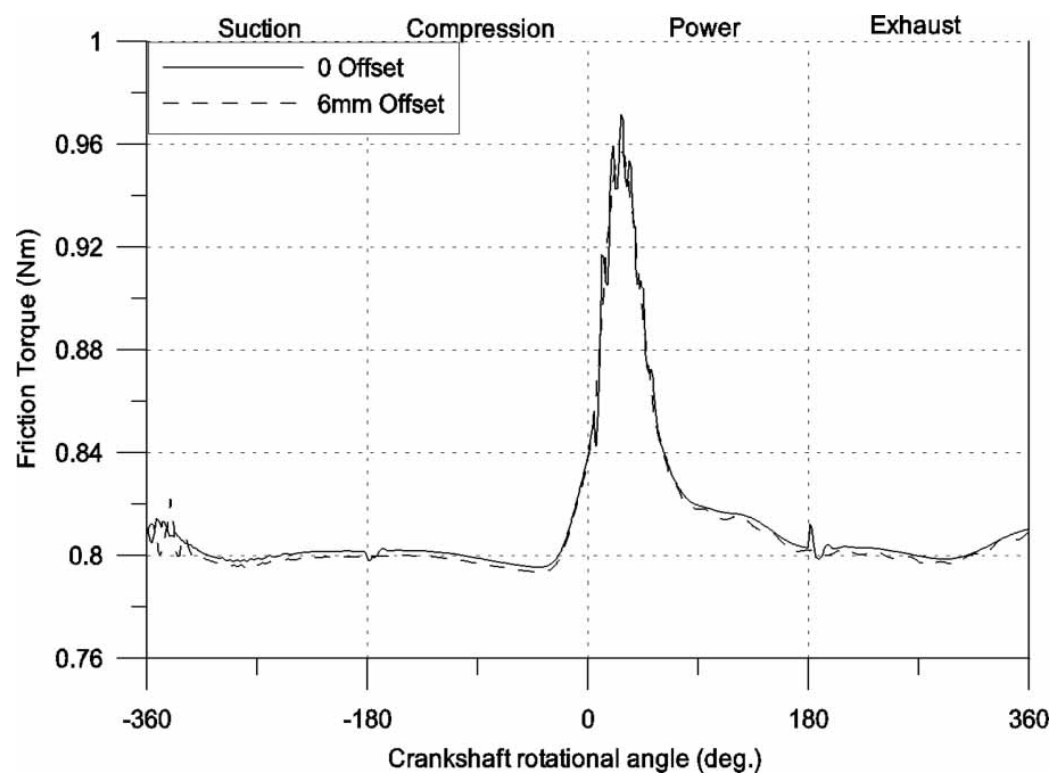

Fig. 21 Main bearing frictional torque variation with crankshaft offset

\section{CONCLUSIONS}

This article presents a multi-physics and multi-scale approach to engine analysis that incorporates inertial and flexible multi-body dynamics, contact mechanics, tribological considerations, and thermal effects at the critical contact conjunctions. The model also caters for boundary friction contribution in the piston skirt and compression ring conjunctions with the cylinder bore. Although this is an important aspect of tribological models and a source of parasitic frictional losses, in the case of the E6 engine, direct surface interactions have not been noted significantly. This is because of rather large piston-bore nominal clearance and relatively low side forces, compared with more modern engines, particularly high-performance variants.

The main contribution of this article is in the integration of load-bearing tribological conjunctions in piston-cylinder interactions and for crankshaft main support bearings. The inclusion of these within a multi-body dynamics model of internal combustion engines provides realistic prediction of forces/reactions that ultimately affect the system dynamics. Analytical solutions, rather than 
time-consuming numerical models, for these conjunctions enable predictive evaluation of engine performance in realistic time scales. The inclusion of thermal effects, an important consideration, in lubricated conjunctions in an analytical manner is another main contribution of the current model.

This article shows that offsetting crankshafts have the desirable effect of reducing frictional losses. The decreased incidence of side-to-side motions of the piston within its clearance space also reduces the piston slapping action.

(C) Authors 2010

\section{REFERENCES}

1 Rahnejat, H. Multi-body dynamics: vehicle, machines, and mechanisms, 1998 (Professional Engineering Publishing, London, UK, and Society of Automotive Engineers, Warrendale, Pennsylvania, USA.

2 Tangasawi, O., Theodossiades, S., and Rahnejat, $\mathbf{H}$. Lightly loaded lubricated impacts: idle gear rattle. $J$. Sound Vib., 2007, 308(3-5), 418-430.

3 Kushwaha, M., Gupta, S., Kelly, P., and Rahnejat, H. Elasto-multi body dynamics of a multi-cylinder internal combustion engine. Proc. IMechE, Part K: J. Multi-body Dynamics, 2002, 216(4), 281-293. DOI: 10. 1243/146441902320992374.

4 Foellinger, H. Advanced CAE simulation and prediction of drivetrain attributes. In Multi-body dynamics: monitoring and simulation techniques-III (Eds H. Rahnejat and S. Rothberg), 2004, pp. 207-219 (Professional Engineering Publishing, London, UK).

5 Dixon, J., Rhodes, D. M., and Phillips, A. V. The generation of engine half orders by structural deformation. In Proceedings of the IMechE Transaction Conference on Vehicle NVH and refinement (MEP), London, pp. 9-17, C487/032/94.

6 Anderson, B. S. Company's perspective in vehicle tribology. In Proceedings of the Leeds-Lyon Symposium on Tribology, 1991, pp. 503-506 (Elsevier Science).

7 Kirk, R. G. and Gunter, E. J. Short bearing analysis applied to rotor dynamics. Trans. ASME, J. Lubr. Technol., 1975, 98(F1), 47-56.

8 Kryniski, K. Jumping phenomenon in journal bearings. Trans. ASME, J. Rotating Mach. Veh. Dyn., 1991, 35, 169-173.

9 Zeischka, J., Mayor, L. S., Schersen, M., and Maessen, F. Multi-body dynamics with deformable bodies applied to the flexible rotating crankshaft and the engine block. In Proceedings of the ASME Fall Technical Conference, Lafayette, Indiana, USA, 1994.

10 Boysal, A. and Rahnejat, H. Torsional vibration analysis of a multi-body single cylinder internal combustion engine model. Appl. Math. Modelling, 1997, 21(8), 481-493.

11 Wakabayashi, R., Takiguchi, M., Shimada, T., Mizuno, Y., and Yamauchi, T. The effects of crank ratio and crankshaft offset on piston friction losses. SAE technical paper 2003-01-0983, 2003.
12 Okamura, H., Shinno, A., Yamanaka, T., Suzuki, A., and Sogabe, K. Dynamic stiffness matrix approach to the analysis of three-dimensional vibrations of automobile engine crankshafts. Part 1. Background and application to free vibrations. In Proceedings of the ASME Winter Annual Meeting, Dallas, Texas, USA, 25-30 November 1990, pp. 47-58.

13 Okamura, H. and Morita, T. Efficient modelling and analysis for crankshaft three-dimensional vibrations under firing conditions. Proc. IMechE, Part K: J. Multibody Dynamics, 1999, 213(1), 33-44. DOI: 10.1243/ 1464419991544036.

14 Craig, R. R. and Brampton, M. C. C. Coupling of substructures for dynamics analysis. AIAA J., 1968, 6, 1313-1319.

15 Perera, M., Theodossiades, S., and Rahnejat, H. A multiphysics multi-scale approach in engine design analysis. Proc. IMechE, Part K: J. Multi-body Dynamics, 2007, 221, 335-348. DOI: 10.1243/14644193JMBD78.

16 Rahnejat, H. Multi-body dynamics: historical evolution and application. Proc. IMechE, Part C: J. Mechanical Engineering Science, 2000, 214(1), 149-173. DOI: 10.1243/0954406001522886.

17 Gohar, R. Elastohydrodynamics, 2001 (Imperial College Press, London).

18 Hamrock, B. J., Schmid, S. R., and Jacobson, B. O. Fundamentals of fluid film lubrication, 2004 (Marcel Dekker Inc., New York).

19 Gohar, R. and Rahnejat, H. Fundamentals of tribology, 2008 (Imperial College Press, London).

20 Cameron, A. The principles of lubrication, 1966 (Longmans, London).

21 D'Agostino, V., Valle, S. D., Ruggiero, A., and Senatore, A. A Study on the piston top ring lubrication using the openend boundary condition. In Proceedings of the AIMETA International Tribology Conference, Italy, 2002.

22 Rahnejat, H. Influence of vibration on the oil film in concentrated contacts. PhD Thesis, Imperial College, University of London, London, 1984.

23 Haddad, S. D. and Tian, K.-T. Analytical study of offset piston and crankshaft designs and the effect of oil film on piston slap excitation in a diesel engine. Mech. Mach. Theory, 1995, 30(2), 271-284.

24 Pinkus, O. and Sternlicht, B. Theory of hydrodynamic lubrication, 1961 (McGraw-Hill, New York).

25 Greenwood, J.A. and Tripp, J. H. The contact of two nominally flat rough surfaces. Proc. Instn Mech. Engrs, 1971, 185, 625-633.

26 Eyring, H. Viscosity, plasticity, and diffusion as examples of absolute reaction rates. J. Chem. Phy., 1936, 4(4), 283-291.

27 Johnson, K. L. Contact mechanics, 1985 (Cambridge University Press, Cambridge).

28 Teodorescu, M. and Taraza, D. Combined multi-body dynamics and experimental investigation for determination of the cam-flat tappet contact condition. Proc. IMechE, Part K: J. Multi-body Dynamics, 2004, 218(3), 133-142. DOI: 10.1243/1464419042035935.

29 Ragot, P. and Rebbert, M. Investigations of crank offset and its influence on piston and piston ring friction behavior based on simulation and testing. In Proceedings of the 2007 World Congress, Detroit, Michigan, 2007, SAE paper 2007-01-1248. 


\section{APPENDIX}

\section{Notation}

A total contact area $\left(\mathrm{m}^{2}\right)$

$A_{\mathrm{a}} \quad$ asperity contact area $\left(\mathrm{m}^{2}\right)$

$A_{\mathrm{h}} \quad$ Hertzian contact area $\left(\mathrm{m}^{2}\right)$

$B \quad$ ring face-width (m)

$c \quad$ journal clearance (m)

$c_{\mathrm{pb}} \quad$ pressure coefficient of boundary shear strength $\left(\mathrm{m}^{2}\right)$

$C_{n} \quad$ constraint function (-)

$C_{\mathrm{p}} \quad$ specific heat at constant pressure $\left(\mathrm{m}^{2} / \mathrm{s}^{2 \circ} \mathrm{C}\right)$

$F_{\mathrm{b}} \quad$ boundary Friction force $(\mathrm{N})$

$F_{n c} \quad$ non-conservative forces (N)

$F_{\mathrm{v}} \quad$ viscous friction force $(\mathrm{N})$

$h \quad$ film thickness (m)

$h_{m} \quad$ minimum film thickness (m)

$h_{m}^{*} \quad$ non-dimensional minimum film thickness, $h_{m} / R\left[h_{m} / R\right]$

$k_{\mathrm{c}} \quad$ thermal conductivity of lubricant $\left(\mathrm{N} / \mathrm{s}^{\circ} \mathrm{C}\right)$

$\ell \quad$ length of the bearing (m)

$p \quad$ pressure $(\mathrm{Pa})$

$p^{*} \quad$ non-dimensional pressure $(\mathrm{Pa})$

$P \quad$ maximum Hertzian pressure $(\mathrm{Pa})$

$P_{\mathrm{a}} \quad$ asperity pressure $(\mathrm{Pa})$

$q \quad$ generalized coordinates (-)

$r_{j} \quad$ journal radius $(\mathrm{m})$

$R \quad$ equivalent radius of ring-liner contact (m)

$T \quad$ kinetic energy (J)

$u_{j} \quad$ journal surface velocity $\left(\mathrm{ms}^{-1}\right)$

$v_{\mathrm{e}} \quad$ coefficient of thermal expansion of the lubricant $\left(\mathrm{m}^{3} /{ }^{\circ} \mathrm{C}\right)$

$V \quad$ potential energy ( $\mathrm{J})$ $w_{\mathrm{s}} \quad$ squeeze velocity $\left(\mathrm{ms}^{-1}\right)$

$w_{\mathrm{s}}^{*} \quad$ squeeze-roll speed ratio, $w_{\mathrm{s}}^{*}=(1 / u)(\partial h / \partial t)$

$W_{x} \quad$ load along the line of centre in journal bearing $(\mathrm{N})$

$W_{z} \quad$ load perpendicular to the line of centre in journal bearing $(\mathrm{N})$

$x \quad$ length along the contact (m)

$\bar{x}$ non-dimensional distance along the contact, $\tan \bar{x}=x / \sqrt{2 R h}$

$x_{\mathrm{r}} \quad$ point of film rupture (m)

$\bar{x}_{\mathrm{r}} \quad$ non-dimensional distance to the film rapture, $\tan \bar{x}_{\mathrm{r}}=x_{\mathrm{r}} / \sqrt{2 R h}$

$X \quad$ piston side (secondary) motion (m)

$y \quad$ distance along the length of bearing $(\mathrm{m})$

$Y \quad$ piston translational (primary) motion (m)

$\alpha \quad$ Included angle (radians)

$\gamma_{\mathrm{s}} \quad$ shear stress dependency on pressure $\left(\mathrm{m}^{2}\right)\left[\mathrm{m}^{2}\right]$

$\Delta u \quad$ sliding velocity $\left(\mathrm{ms}^{-1}\right)$

$\varepsilon \quad$ eccentricity ratio $(-)$

$\eta \quad$ dynamic viscosity (Pa-s)

$\eta_{0} \quad$ atmospheric dynamic viscosity (Pa-s)

$\theta \quad$ temperature $\left({ }^{\circ} \mathrm{C}\right)$

$\theta_{\mathrm{e}} \quad$ Effective contact temperature $\left({ }^{\circ} \mathrm{C}\right)$

$\theta_{1} \quad$ inlet temperature $\left({ }^{\circ} \mathrm{C}\right)$

$\lambda \quad$ Stribeck's oil film parameter (-)

$\rho \quad$ lubricant density $\left(\mathrm{kg} / \mathrm{m}^{3}\right)$

$\sigma \quad$ root mean square surface roughness of counterfaces (m)

$\tau \quad$ shear stress $(\mathrm{Pa})$

$\tau_{\mathrm{e}} \quad$ Eyring shear stress $(\mathrm{Pa})$

$\tau_{0} \quad$ limiting shear stress (Pa)

$\vartheta \quad$ Piston tilt (radians) 